\title{
Conflicterende gezondheidsadviezen betreffende vitamine D: hoe maken ouders een afweging?
}

\author{
Aniek van de Griendt \\ Maastricht University \\ a.vandegriendt@student.maastrichtuniversity.nl
}

\begin{abstract}
Introductie. Vitamine D wordt vooral verkregen via zonlicht en is een belangrijke nutriënt voor een goede ontwikkeling van kinderen. Voldoende blootstelling aan zonlicht is dus gewenst bij jonge kinderen, maar blootstelling aan de zon wordt ook geassocieerd met verbranding en huidkanker. Dit paper beschrijft het onderzoek naar de manier waarop ouders van kinderen tot vier jaar een keuze maken tussen de tegenstrijdige gezondheidsadviezen betreffende voldoende vitamine $D$ inname voor kinderen uit de zon en de gezondheidsadviezen betreffende het vermijden van blootstelling aan te veel zon ter preventie van verbranding en huidkanker. Methode. In dit onderzoek is gebruik gemaakt van kwalitatief onderzoek met semigestructureerde interviews. Tien autochtone ouders met tenminste één kind in de leeftijd tot vier jaar werden bij hen thuis geïnterviewd. De vragenlijst bestond uit vragen over persoonskenmerken, algemene vragen over vitamine $D$, en open vragen die de onderzoeksvragen dekten. Alle transcripten werden aan de hand van de onderzoeksvragen en het theoretisch kader gecodeerd in het computerprogramma NVivo. Resultaten. De meeste participanten hadden nog nooit over het bestaan van conflicterende adviezen nagedacht. De meerderheid gaf aan, net zoals met de andere adviezen, te kiezen voor het advies waar zij het meest achterstond of het beste bij de situatie vond passen. Alle participanten vonden het belangrijker dat hun kind niet zou verbranden, met de consequentie dat deze dan onvoldoende vitamine D op zou doen. Dit werd onderbouwd met het feit dat de participanten hun kinderen supplementen gaven om toch voldoende vitamine D binnen te krijgen. Conclusie. Opvallend is dat de meeste ouders niet erkennen dat de gezondheidsadviezen die zij krijgen conflicterend kunnen zijn. In de gezondheidsvoorlichting zou hierop moeten worden ingespeeld, zodat ouders een beter afgewogen keuze kunnen maken.
\end{abstract}




\section{Trefwoorden}

Conflicterende gezondheidsadviezen, vitamine D, zonbescherming, Protectie Motivatie Theorie

\section{Inleiding}

Eén van de belangrijke nutriënten bij de lichamelijke ontwikkeling van kinderen is vitamine

D. Volgens de Gezondheidsraad (2012) is vitamine D nodig voor een goede opname van calcium en fosfor uit voeding en heeft het lichaam vitamine $D$ nodig voor stevige tanden en botten. Vitamine $D$ houdt osteoporose en andere botaandoeningen tegen en speelt een rol in de celdeling en celregulatie (Gezondheidsraad, 2012). Bijna de gehele aanbevolen hoeveelheid (90\%) van vitamine D halen de meeste mensen uit blootstelling aan zonlicht (Holick, 2004). Het wordt aanbevolen om elke dag vijf tot vijftien minuten met je handen en hoofd onbedekt zonlicht tot je te nemen, tussen elf uur 's ochtends en drie uur 's middags (Gezondheidsraad, 2012). De productie van vitamine D door blootstelling aan de ultraviolette B-straling uit zonlicht wordt beïnvloed door meerdere factoren (Holick, 2004). Deze factoren zijn de duur van de blootstelling, intensiteit van de uv-straling, tijd op de dag en van het jaar, huidtype, de hoeveelheid pigment in de huid en de leeftijd van de persoon. Langere tijd in de zon zitten verhoogt de aanmaak van vitamine $D$, maar na een half uur neemt de aanmaak af (Holick, 2004).

Vitamine $\mathrm{D}$ kan ook worden opgenomen uit bepaalde voeding, maar deze bijdrage is te weinig zonder voldoende blootstelling aan zon of eventuele supplementen (Gezondheidsraad, 2012). Volgens de Gezondheidsraad kan vitamine D uit (vette) vissoorten, zoals zalm en makreel, leverproducten, melkproducten en eieren worden opgenomen (Gezondheidsraad, 2012). Echter krijgen jonge kinderen tot vier jaar oud van deze voedingsbronnen te weinig binnen voor voldoende aanmaak van vitamine $D$. Kinderen in deze leeftijdsgroep zouden 10 microgram vitamine D per dag binnen moeten krijgen. Door de Gezondheidsraad wordt aangeraden om deze kinderen een supplement te geven met daarin 10 microgram vitamine $D$, omdat zij moeilijk via natuurlijke bronnen aan de aanbevolen hoeveelheid vitamine D komen (Gezondheidsraad, 2012).

De meeste efficiënte bron van vitamine $D$ is dus ultraviolette straling, maar deze straling kan ook schadelijk zijn. Zonnebrand en te veel blootstelling aan zonlicht kunnen schade aan de huid en daarbij veel pijn veroorzaken. Zonnebrand tijdens de kindertijd is een risicofactor voor de ontwikkeling van huidkanker op latere leeftijd (Holick, 2004). Voor de preventie van huidkanker wordt het aangeraden om de huid altijd te beschermen 
met antizonnebrand, door beschermende kleding te dragen, en de zon te mijden tussen twaalf en drie uur's middags (de Groot \& Toonstra, 2010). Dit advies is tegenstrijdig aan het advies voor de inname van vitamine D. Mensen moeten dus keuzes maken tussen verschillende gezondheidsadviezen, waarbij het vaak de ouders zijn, die deze keuzes maken voor hun kinderen. Hoe ouders kiezen tussen tegenstrijdige gezondheidsadviezen, wordt in dit onderzoek onderzocht.

Om te kunnen verklaren waarom ouders bepaalde gezondheidsadviezen opvolgen voor hun kinderen en andere adviezen niet, moet inzicht verkregen worden in factoren die de keuze beïnvloeden. Een theorie die kan worden gebruikt om gedrag te verklaren, is de Protectie Motivatie Theorie (PMT) van Rogers (1975). Het model verklaart hoe men tot een 'adaptieve respons' komt, gedrag dat gericht is op het beschermen van eigen gezondheid, en hoe men tot een 'maladaptieve respons' komt, gedrag dat niet goed is voor de eigen gezondheid (Figuur 1) (Rogers, 1983). De ernst van de bedreiging samen met de persoonlijke kwetsbaarheid bepalen in dit model hoe hoog de dreiging wordt ingeschat. Twee aspecten zijn bepalend voor de inschatting van de coping-strategieën, namelijk de verwachting dat het aanbevolen advies leidt tot een vermindering van de gezondheidsbedreiging (responseffectiviteit) en de verwachting of het aanbevolen advies door de individu uit te voeren is (eigen-effectiviteitsverwachting) (Rogers, 1983). Wanneer de responseffectiviteit en eigen-effectiviteitsverwachting groot zijn en de nadelen van het gewenste gezondheidsgedrag (respons kosten) klein zijn, wordt de kans op het uitvoeren van een adaptieve respons groter. De protectie motivatie wordt uitgelegd als de intentie om een gezondheidsadvies uit te voeren (Rogers, 1983).

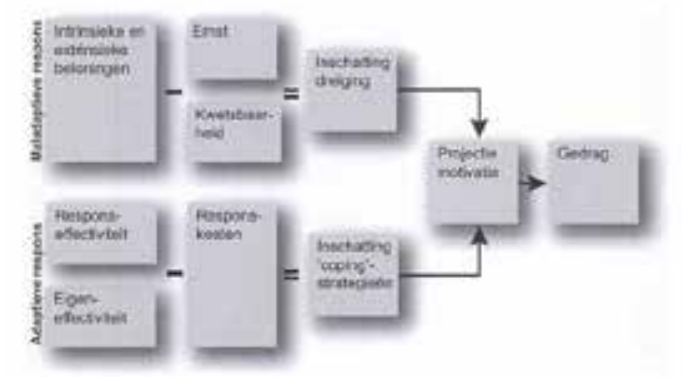

Figuur 1. De Protectie Motivatie Theorie (Rogers, 1983, blz. 168)

Het gewenste gedrag in dit onderzoek is voldoende vitamine D inname bij kinderen. Bij dit onderzoek zal worden gekeken hoe ouders proberen tot dit gewenste gedrag te komen. De 
dreiging in dit onderzoek bestaat uit twee delen, namelijk dreiging van vitamine $D$ tekort bij kinderen en dreiging van zonnebrand door te veel blootstelling aan zonlicht. In welke mate ouders inschatten hun kinderen tegen deze dreigingen te kunnen beschermen zal invloed hebben op het wel of niet uitvoeren van het gewenste gedrag.

Aan de hand van de achtergrondinformatie en de gebruikte theorie is de volgende onderzoeksvraag geformuleerd: 'Hoe maken ouders van kinderen in de leeftijd tot vier jaar een afweging tussen de tegenstrijdige gezondheidsadviezen betreffende voldoende vitamine $D$ inname voor kinderen uit de zon en de gezondheidsadviezen betreffende het vermijden van blootstelling aan te veel zon ter preventie van verbranding en huidkanker?'

\section{Methode}

In dit onderzoek is gebruik gemaakt van kwalitatief onderzoek. Bij kwalitatief onderzoek wordt vanuit een bepaalde vraagstelling gekeken naar attitudes en gedragingen van een groep mensen rondom een bepaald onderwerp. Kwalitatief onderzoek wordt vaak gedaan door het afnemen van interviews (Boeije, 2005). De interviews in dit onderzoek waren semigestructureerd, wat betekent dat open vragen aan de hand van een topiclijst werden gesteld. De vragen waren dus voorbereid, maar tijdens het interview zelf konden de volgorde en de manier van vragen bepaald worden. Op de vragenlijst in dit onderzoek stonden vragen over persoonskenmerken, algemene vragen over vitamine $D$ en open vragen die de onderzoeksvragen dekten.

De onderzoekspopulatie in dit onderzoek bestond uit autochtone ouders met tenminste één kind in de leeftijdsgroep tot vier jaar. Alle respondenten moesten woonachtig zijn in Zuid-Limburg. Het afnemen van de interviews gebeurde in de meeste gevallen door twee onderzoekers, waarbij één iemand het interview afnam en de ander als observator aanwezig was. In een enkel geval werd een interview door één persoon afgenomen. Alle interviews duurden ongeveer dertig minuten en werden bij de participanten thuis gehouden. Nadat de interviews afgenomen waren, werd de data uitgewerkt in een transcript.

Alle getranscribeerde interviews werden daarna ingevoerd in het computerprogramma NVivo. NVivo is een programma dat helpt om data te ordenen. Aan de hand van het theoretisch kader en de onderzoeksvragen werden free nodes gecreëerd, zoals 'kennis', 'ernst van vitamine D tekort' en 'eigeneffectiviteit'. De stukken tekst uit de verschillende interviews werden gecodeerd als een van deze nodes. Hierna konden de resultaten worden geschreven. 


\section{Resultaten}

Voor dit onderzoek zijn van de elf genodigden tien participanten geïnterviewd. De respons in dit onderzoek was dus hoog. Alle participanten waren vrouwelijk en hadden een leeftijd tussen de 25 en 35 jaar, met een gemiddelde leeftijd van 29 jaar. Acht van de participanten hadden één kind, en de overige twee participanten hadden twee kinderen. Drie vrouwen hadden MBO als opleidingsniveau, zes vrouwen waren $\mathrm{HBO}$ geschoold en één vrouw had WO als opleidingsniveau. Op één participant na hadden alle participanten op het moment van onderzoek minimaal één kind in de leeftijd tot vier jaar, één participant had echter een kind van vier jaar.

De gezondheidsadviezen die ouders kregen kwamen van verschillende bronnen, waarbij het consultatiebureau door alle ouders als bron werd genoemd. Andere bronnen waar de participanten adviezen vandaan haalden waren: eigen literatuur, vrienden, familie, (fora op) het internet, de huisarts, de kraamverzorging, tijdschriften over kinderen, de verloskundige, andere ouders en kennissen. Op de vraag hoe de participanten bepaalden welk advies ze wel of niet wilden opvolgen werd vaak geantwoord dat ze voor zichzelf nadachten welk advies ze het meest bij de situatie vonden passen en waar ze zelf het meest achterstonden. Ook werd geantwoord dat participanten de meningen van andere mensen wel mee zouden nemen in een afweging, maar uiteindelijk zouden gaan voor het advies waar zij als moeder en vader het meest achter zouden staan.

Wanneer in het interview werd voorgelegd dat bepaalde adviezen, zoals die over zonnebrand en vitamine D opname uit de zon, erg tegenstrijdig zijn was de eerste reactie van de participanten in meerdere gevallen dat ze hier nog nooit over nagedacht hadden. Een aantal van de participanten gaf als reactie dat het typisch was voor het consultatiebureau om tegenstrijdig advies te geven. De meeste participanten gaven aan, net zoals met de andere adviezen, te kiezen voor het advies waar zij het meest achterstonden of het beste bij de situatie vonden passen. Eén participant zei de middenweg te kiezen bij tegenstrijdige adviezen, dus om in het voorbeeld van dit onderzoek haar kind korte tijd onbeschermd in de zon te laten voor vitamine $\mathrm{D}$ en haar daarna in te smeren, tegen verbranding.

Alle participanten hadden vóór de interviews al van het bestaan van vitamine $D$ gehoord. Echter wisten niet alle participanten wat de natuurlijke bronnen van vitamine D waren. Ook wist niet iedereen wat het belang was van het geven van voldoende vitamine $D$ aan de kinderen. Negen van de tien participanten gaf haar kind(eren) wel een vitamine $D$ supplement, in de vorm van pilletjes of in de vorm van druppels. Een van de redenen voor 
het geven van vitamine $D$ supplementen was dat participanten het belangrijk vonden dat hun kinderen toch voldoende vitamine D binnen zouden krijgen, als dat door voeding en zonlicht alleen niet zou lukken. Volgens een aantal participanten leverde de gedachte dat het niet geven van vitamine $D$ zou leiden tot schade aan het kind een schuldgevoel op, en daarom werd besloten om vitamine $D$ te geven. Omdat de kinderen de supplementen lekker vonden, gaven de participanten aan dat er vrij weinig moeilijkheden ondervonden werden bij het geven van de supplementen.

Een aantal van de participanten gaf aan dat ze zich zorgen zou maken als haar kind te weinig vitamine $\mathrm{D}$ binnen zou krijgen. De kans op botbreuken was een reden van zorg voor een deel van de participanten. Sommige participanten maakten zich geen zorgen bij een eventueel vitamine $D$ tekort. Meerdere participanten merkten in het interview op dat alle gezondheidsrisico's zo ver weg lagen, en dat er altijd wel een kans is dat je iets krijgt, dus dat ze zich daarom geen zorgen maakten.

Uit alle interviews kwam naar voren dat de participanten het belangrijker vonden dat hun kinderen niet zouden verbranden, met de consequentie dat ze dan onvoldoende vitamine $\mathrm{D}$ op zouden doen. Dit werd onderbouwd met het feit dat de participanten hun kinderen supplementen gaven om toch voldoende vitamine D binnen te krijgen. Geen van de participanten antwoordde dat ze haar kind onbeschermd in de zon liet spelen, met de bedoeling vitamine $\mathrm{D}$ op te doen. Wel werd gezegd dat met de informatie die de participanten in het interview verkregen hadden over vitamine D opname door de zon, ze het in de overwegingen mee zouden kunnen nemen. Een aantal participanten noemde naast verbranding ook huidkanker als een gezondheidsrisico van onbeschermd in de zon zijn. In één van de interviews werd aangegeven dat de participant steeds meer gevallen van huidkanker hoorde, dus smeerde ze haar kind in uit voorzorg. De participanten die niet aangaven meteen aan huidkanker te denken, gaven aan daar te optimistisch voor te zijn of daar nog niet aan te willen denken omdat dat te ver weg lag. De directe gevolgen van zonnebrand, dus de pijn die het bij het kind zou kunnen veroorzaken, wogen zwaarder op dan de gevolgen op langere termijn.

In het kader van eigen-effectiviteitsverwachting bleek dat niet alle participanten het altijd even makkelijk vonden om hun kinderen beschermd bloot te stellen aan de zon. Een participant vertelde dat ze niet altijd aan het insmeren van haar kind dacht en uit de interviews bleek ook dat meerdere participanten moeite hadden om het insmeren weer in het dagelijks ritme te krijgen, als de zon in de lente weer begon te schijnen. Participanten gaven aan dat het insmeren in de zomer wel in het dagelijks ritme zat. 


\section{Discussie}

Met dit onderzoek is onderzocht hoe ouders van jonge kinderen een afweging maken tussen conflicterende gezondheidsadviezen, waarbij speciaal gekeken is naar de conflicterende gezondheidsadviezen met betrekking tot voldoende vitamine D opname uit de zon en het beschermen van kinderen tegen zonnebrand. Hoewel er al eerder onderzoek is gedaan naar vitamine $D$ gebruik van jonge kinderen en bescherming van kinderen tegen de gevaren van blootstelling aan de zon, is nog niet eerder onderzocht hoe ouders een keuze maken tussen beide gezondheidsadviezen.

\section{Beantwoorden van de probleemstelling}

In dit onderzoek zijn de theoretische concepten van de Protectie Motivatie Theorie gebruikt om tot een verklaring van het gedrag te komen. Het gewenste gedrag in dit onderzoek was voldoende vitamine $\mathrm{D}$ opname bij kinderen, waarbij onderscheid kon worden gemaakt in twee dreigingen. Zo werden zowel onvoldoende vitamine $D$ inname bij kinderen tot vier jaar, als zonnebrand door te veel blootstelling aan zonlicht als dreiging beschouwd. Uit dit onderzoek blijkt dat weinig mensen weten wat bronnen van vitamine D zijn. Ook kon maar een klein deel van de geïnterviewde moeders noemen dat vitamine $D$ belangrijk is voor botten. Uit eerder onderzoek kon al geconcludeerd worden dat de algemene kennis over vitamines bij ouders laag is (Ko, Ramsell \& Wilson, 1992). In de interviews gaf iedereen wel aan ooit informatie over vitamine $D$ verkregen te hebben.

Een belangrijk resultaat dat gebleken is uit de interviews is dat niet iedereen dacht dat kinderen kwetsbaar waren bij een vitamine D tekort. Dit komt doordat gezondheidsrisico's pas later in het leven opspelen en ook werd geconcludeerd dat het met de moeders zelf ook goed was gekomen, dus dat de kinderen geen risico liepen. De risicoperceptie kan dus bij de groep ouders als laag worden beschouwd. Dit kan door middel van literatuur over risicoanalyses verklaard worden. Risico's die pas op lange termijn een bedreiging vormen worden laag geschat in de risicoperceptie (International Risk Governance Council, 2005). De inschatting van een risico is over het algemeen ook klein als uit eigen ervaring is gebleken dat risico's niet tot een dreiging hebben geleid (International Risk Governance Council, 2005).

Uit de interviews kwam duidelijk naar voren dat onder de moeders een groot bewustzijn van de schadelijke gevolgen van blootstelling aan de zon heerst. Een belangrijk resultaat uit dit onderzoek is dat verbranding werd gezien als grootste gezondheidsrisico van onbeschermd aan de zon blootgesteld zijn. Dit is een resultaat dat van tevoren al 
verwacht werd, en wordt ondersteund door het onderzoek van Zinman, Schwartz, Gordon, Fitzpatrick \& Camfield (1995). Zij concludeerden in hun onderzoek dat ouders zonnebrand als grootste risico zien van onbeschermd aan de zon blootgesteld zijn (Zinman. et al., 1995). Een deel van de geïnterviewde moeders keek naast verbranding ook naar de gevolgen op langere termijn, en noemde ook huidkanker als risico. Bij de beslissing om kinderen in te smeren wogen de gevolgen op korte termijn wel veel zwaarder dan een eventueel risico op langere termijn.

Geen van de moeders uit dit onderzoek liet haar kind bewust onbeschermd de zon in om zo vitamine $\mathrm{D}$ op te nemen. Onbeschermd in de zon komen werd gezien als te onveilig en het bijbehorende risico dat kinderen vitamine $D$ tekort zouden komen werd ontkracht met het argument dat ouders hun kinderen een vitamine D supplement gaven. Blijkbaar is de dreiging van een vitamine $D$ tekort in dit geval te klein om als adaptieve respons te fungeren, tegen de dreiging van verbranden. Uit de interviews kwam wel naar voren dat na het houden van het interview werd ingezien dat het niet alleen schadelijk is om onbeschermd in de zon te komen.

Een keuze tussen gezondheidsadviezen werd in de meeste gevallen op eigen instinct gemaakt. Adviezen werden over het algemeen gezien als aanvullend materiaal, maar er waren ook moeders die aangaven een advies zonder verder na te denken op te volgen. Het feit dat menig gezondheidsadvies een ander advies tegenspreekt bleek niemand te zijn opgevallen vóór het interview. Doordat ouders zo veel adviezen krijgen, lijken zowel het bewustzijn van deze verschillende adviezen als de kritische noot voor deze adviezen weg te vagen. In de interviews kwam naar voren dat het typisch werd gevonden dat consultatiebureaus tegenstrijdige adviezen gaven. Bij tegenstrijdige adviezen werd gekozen voor het advies dat het best bij de situatie paste, of werd voor een middenweg gekozen.

\section{Beperkingen}

In dit onderzoek gaven alle moeders aan te kiezen voor het beschermen van hun kind tegen de zon om verbranding te voorkomen en niet voor het in de zon laten voor opname van vitamine $D$, omdat zij toch al supplementen gaven. Het feit dat alle participanten in dit onderzoek hun kinderen vitamine $\mathrm{D}$ supplementen gaven, is dus een beperking van dit onderzoek. Dit had voorkomen kunnen worden door de onderzoekspopulatie nog verder te specificeren tot ouders van kinderen tot vier jaar die geen vitamine D supplementen geven aan hun kinderen. 
Een andere beperking in dit onderzoek is dat de steekproef alleen uit moeders, en niet ook uit vaders bestond. Dit kan tot een vertekening in de resultaten hebben geleid, omdat moeders anders kunnen zijn ingelicht over adviezen dan vaders. Moeders hebben zich vaak beter ingelezen over gezondheidskwesties en zijn eerder geneigd zelf advies op te zoeken. Ook is uit eerder onderzoek naar het beschermen van kinderen tegen zonnebrand gebleken dat moeders een positievere attitude hebben ten aanzien van het beschermen van het kind dan vaders (Cercato, Nagore, Ramazzotti, Sperduti \& Guillén, 2013)

In alle tien de interviews kwamen nieuwe inzichten naar voren, waardoor er geen precieze resultaten gevonden zijn. Dat in dit onderzoek gebruik is gemaakt van semigestructureerde interviews is hierbij een voordeel, omdat de nieuwe inzichten hierbij wel volledig zijn.

\section{Aanbevelingen voor praktijk en onderzoek}

Omdat in dit onderzoek steeds nieuwe inzichten aan het licht kwamen, is het belangrijk om meer onderzoek uit te voeren naar de motivatie van ouders om te kiezen tussen conflicterende adviezen. Om uit te vinden wat nu de belangrijkste reden is om te kiezen tussen adviezen, zal kwantitatief onderzoek verricht moeten worden. Dit onderzoek werd beperkt door het feit dat alle ouders hun kinderen voldoende vitamine D gaven door middel van supplementen of groeimelk. In een volgend onderzoek zou de onderzoekspopulatie dus beter kunnen bestaan uit ouders van kinderen tot vier jaar die hun kinderen geen vitamine D supplementen geven. Verder blijkt het zo te zijn dat onder ouders geen bewustzijn heerst voor tegenstrijdige adviezen. Hier zal dus in de gezondheidsvoorlichting op moeten worden ingespeeld. Het is daarbij belangrijk dat vanuit de kant van de voorlichting moet worden erkend dat adviezen kunnen conflicteren en dat dit op een goede manier wordt doorgegeven aan de mensen die de voorlichting ontvangen.

\section{Conclusie}

Dit onderzoek heeft aangetoond dat ouders niet door hebben dat de adviezen die zij ontvangen kunnen conflicteren. Vanuit de gezondheidsvoorlichting zal hier dus op ingespeeld moeten worden. Op grond van dit onderzoek en de beperkingen kunnen we ook concluderen dat meer onderzoek moet worden uitgevoerd om de belangrijkste reden voor ouders om een keuze te maken tussen adviezen te bepalen. 


\section{Rol van de student}

Voor dit onderzoek heeft Aniek van de Griendt in een thesisgroep van in totaal vier studenten samengewerkt om verschillende aspecten van voldoende vitamine $D$ inname bij jonge kinderen te onderzoeken. De onderzoeksvragen zijn gezamenlijk geformuleerd en de interviews zijn in tweetallen gehouden. Het schrijven van de thesis en het verwerken van de resultaten gebeurden individueel. Ook behoorde het wekelijks geven van feedback op de stukken van de andere studenten tot de rol van de student.

\section{Referenties}

1. Boeije, H. (2005). Analyseren in kwalitatief onderzoek. Amsterdam: Boom Uitgevers.

2. Cercato, M. C. , Nagore, E., Ramazzotti, V., Sperduti, I. , \& Guillén, C. (2013). Improving Sun-Safe Knowledge, Attitude and Behaviour in Parents of Primary School Children: a Pilot Study. Journal of Cancer Education, $28,151-157$

3. Gezondheidsraad (2012). Evaluatie van de voedingsnormen voor vitamine D. Den Haag: Gezondheidsraad.

4. De Groot, A. C. , \& Toonstra, J. (2010). Kanker en huid. Houten: Bohn Stafleu van Loghum.

5. Holick, M. F. (2004). Sunlight and vitamin D for bone health and prevention of autoimmune diseases, cancers, and cardiovascular disease. The American Journal of Clinical Nutrition, 80, 1678-1688.

6. International Risk Governance Council (2005). Risk Governance - Towards an Integrative Framework. Genève: International Risk Governance Council. Opgehaald 20 april, 2015, van http://irgc.org/wpcontent/uploads/2012/04/IRGC_WP_No_1_Risk_Governance_reprinted_version_3.pdf

7. Ko, M. L. B. , Ramsell, N. , \& Wilson, J. A. (1992). What do parents know about vitamins? Archives of Disease in Childhood, 67, 1080-1081.

8. Rogers, R. W. (1975). A protection motivation theory of fear appeals and attitude change. Journal of Psychology, 91, 93-114.

9. Rogers, R. W. (1983). Cognitive and physiological processes in fear appeals and attitude change: A Revised theory of protection motivation. In J. T. Cacioppo, \& R. E. Petty (Eds.), Social Psychophysiology: a source book (blz. 153-176). New York: Guilford Press.

10. Zinman, R. , Schwartz, S. , Gordon, K. , Fitzpatrick, E. , \& Camfield, C. (1995). Predictors of sunscreen use in childhood. Archives of pediatrics \& adolescent medicine, 149, 804-807. 